\title{
Creation of Anticipatory Information Support for Virtual Organizations between System(S) Theory and System Thinking
}

\author{
Vojko Potocan and Matjaz Mulej \\ University of Maribor, Maribor, Slovenia
}

vojko.potocan@uni-mb.si mulej@uni-mb.si

\begin{abstract}
A requisitely holistic information support can help us improve our business operation, but such information is hard to attain and even harder to attain in virtual organizations presenting a specific, more fluid form of business systems. Important difficulties include complexity and complicatedness, time (real and future, and their difference from the past), information requirements (realistic definition of them and meeting them), and related methodological problems. Anticipation capability may help business systems develop into anticipatory ones and develop their prevailing thinking style into the anticipatory system thinking (aimed at requisitely holistic mastering of the potential future, even a virtual one).
\end{abstract}

Keywords: Anticipation, Anticipatory Business System, Anticipatory System Thinking, Enterprise resource planning, System(s) Theory, Virtual organization.

\section{Introduction}

Contemporary life is complex. So is anticipation of the events to come. (See definition of anticipation in Potocan, 2002.) That is why many discuss modern trends in anticipation, and its application in business systems (BSs). (See definition of a system and essential related terms in Mulej, 2000; Mulej, 2001; Mulej, Bastic et al., 2003; Mulej, Zenko et al., 2003). But the problem is, that humans act somewhere between mastery and mystery, because we have to work and live with the unknowable, and manage with the unmanageable (Flood, 1999; Mulej, 2000; Potocan, 2000). Information systems may make the situation easier. (See definition of information systems in Noris, Hurley, Dunleavy \& Balls, 2000.)

This is especially important for BSs. They belong to the most influential institutions of the modern age. It is almost impossible to reach any goal in the society without engaging organizations or humans as BSs, i.e. entities interested in benefit, e.g. profit, and investing mental and physical effort, time, and money as resources for it. And therefore the paper discusses three theses.

The first thesis: it is possible to create more suitable (e.g. more holistic) information solutions to support operations of virtual organizations. In this framework we are trying, first, to define im-

Material published as part of these proceedings, either on-line or in print, is copyrighted by Informing Science. Permission to make digital or paper copy of part or all of these works for personal or classroom use is granted without fee provided that the copies are not made or distributed for profit or commercial advantage AND that copies 1) bear this notice in full and 2) give the full citation on the first page. It is permissible to abstract these works so long as credit is given. To copy in all other cases or to republish or to post on a server or to redistribute to lists requires specific permission from the publisher at Publisher@InformingScience.org portant attributes required from information systems for them to be usable in virtual organizations. Then, once we will have found preconditions and requirements for conceptualization of information support, we will discuss enterprise resource planning 
(ERP) as a potential solution supportive of a virtual organization at work.

The second thesis: the functioning of BSs (and of course, the virtual organization, as a possible form of their functioning) can profit from the application of the Anticipatory System (AS) rather than from a shortsighted behavior. The necessary starting point for creation of AS is provided by a new approach to business operations and a new mental model - the Anticipatory System Thinking (AST). The anticipatory BS significantly influences all levels and activities of business functioning, mainly by its ability to ensure / support a future oriented functioning, behavior appropriate in relation to the BS's environment as well as leading to flexibility and ergodics.

The third thesis: control over functioning of the anticipatory BS (when we speak about BS in general and when we speak about specific sorts, types and forms of BSs, as ERP in our case) can become deeper once humans understand the complex and complicated reality of business operation (Potocan, 1998, 2000, 2002; Potocan, Rebernik, \& Mulej, 2003). By researching we wish to detect the methodological support for definition and creation of requisitely holistic anticipatory BS. Hence, we discuss some basic characteristic of relations between Anticipation, Systems Theories, System Thinking, and their synergies.

\section{Provision of Information Support for Virtual Organizations}

\section{The Usual Information Systems for Virtual Organizations}

The information technology supporting the virtual organization model varies, ranging from simple communication technology such as e-mail, fax and teleconferencing to groupware, videoconferencing and inter-organizational linkages such as EDI (Davidow \& Malone, 1995; Goldman, Nagel \& Preiss, 1995; Palmer, 1998). All services mentioned are Internet services. Where and when a virtual organization applies a distinct information technology and information system, it depends on the content and on the characteristics of co-operation.

The business process of a virtual organization is organized according to models as a basis for workflow between partners. A comprehensive and sustainable model for all co-operation processes is problematic to construct. The problem is to some extent a question of stable structures in co-operation processes. The most structured and frequently reoccurring processes are called predetermined processes. Unique and flexible processes, which are un-structured, are called ad-hoc processes. Processes in between these extremes are referred to as semi-structured processes. Each process type within a virtual organization requires a different information system.

Unstructured and semi-structured processes offer limited possibilities for workflow automation. Less structured co-operation processes can be supported, if one supplies employees with a set of diverse communication media, each consisting of certain functionalities. The most suitable for this type of processes are the information systems, which are based on technologies for computer supported co-operative work (CSCW). Approaching this question a virtual organization has first to develop a layer framework, which provides a description of the relationship between coordination and co-operation processes, the underlying human communication processes, and communication media (Englert, Eymann, Hummel \&Schoder, 1996). Then a document based information system can be developed if one uses groupware technology (e.g. Lotus Notes). Such information systems should provide the user with a toolbox, which contains a sufficient set of communication media to deal with a specific context.

On the other hand, structured and predetermined processes require workflow automation and inter-organizational information systems, which support data exchange between information systems of partners in a virtual organization (Davidow \& Malone, 1995; Goldman et al., 1995). A 
workflow information system is under control of the responsible person with relevant support and the necessary data at the right point in the process. They also allow organizations to dynamically define, execute, manage, and modify business processes. The workflow information system controls the process flow. It connects the screen forms needed for data to be input and output at every step in the process. Workflow information systems are suited for well-structured processes, where clearly defined rules determine the execution order of the process steps.

In the last few years, however, we have seen a growing tendency towards package-ware. Information systems in areas such as sales and marketing, production and procurement are supported by enterprise resource planning (ERP) solutions. The ERP systems automate generic versions of the business process, often internally using a workflow engine for process customization, control and automation. In recent years we have also seen a growing tendency towards seamless integration of business processes in virtual organizations. Information technology and the Internet play a crucial role here. Global companies use the Intranet or Extranet to communicate internally using Internet technologies. But the integration of business processes does not stop at company boundaries. Supply chain processes are integrated using web and other e-commerce technologies from the supplier through the producer to the consumer (Gloor, 2000; Palmer, 1998). To link business processes in virtual organizations, the underlying information systems needs the capability to link information seamlessly and automatically.

\section{Enterprise Resource Planning (ERP) Solutions in Virtual Organizations}

ERP solutions provide support in areas such as accounting and controlling, production and material management, quality management and plant maintenance, sales and marketing, project management, and human resources. Leading vendors of ERP solutions for large companies are SAP, Oracle, Baan, etc. SAP is by far the largest ERP vendor (Gloor, 2000; Palmer, 1998). With its MySAP.com initiative, it is moving quickly into e-business area, combining SAP standard business applications with standard Internet technologies. ERP and e-business integration defines new information systems architecture of virtual organizations, which can be described as ERP based ebusiness.

ERP based E-business improves business performance by using information technologies and open standards to connect suppliers, partners and customers at all steps along the value chain. These information systems can significantly improve business performance by strengthening the linkages in the value chain between businesses, and between a business and its ultimate customer. Streamlining of business processes in virtual organizations involves two imperatives: trust among business partners and agreement on standard ways of working, and agreement on common data exchange standards that facilitates dialogue on mutual business events over the Internet. This applies to virtual organizations, too. Why?

Different authors (See: Österle, Fleisch \& Alt, 2000) suggest a model that reflects major principles of the networked enterprise - virtual organization. Its four building blocks are:

- Networked processes - e-business enables direct co-operation between partners and organization core processes

- Business bus - e-business enables co-operation between partners based on a high level of standardization

- Electronic services - e-business enables co-operation with externalized services

- Service integrator - e-business enables co-operation with new players - »infomediaries « - within business networking. 
All these processes / blocks are linked into one entity by information. They require resources. In order to make rational decisions about how to deploy resources in implementing ERP based ebusiness, a virtual company must know both its starting position in the e-business panorama and its desired end state, related to the various possibilities. The ERP/e-business matrix (Noris et al., 2000) defines five scenarios for an ERP based e-business:

- Channel enhancement - modifying existing business processes

- Value-chain integration - integrating suppliers, partners and customers through e- business customer relationship management (eCRM) and through e-business supply chain management (eSCM)

- Industry transformation - restructuring virtual organization

- Convergence - partnering with companies from different industries.

ERP based e-business information systems require extended ERP functionality. In the e-world, the focus is no longer just on how well an ERP system can store and manage data and move it around within the company. It rather tackles both adding value to that data in order to turn it into information and knowledge, and moving that data and information across virtual organization to create knowledgeable extended organizations. Some areas in which ERP systems will be expanded are:

- Web based customer relationship management (eCRM), which has to support ecommerce and data mining

- Advanced planning and scheduling which has to provide a better way of managing information flow connected with manufacture resource planning

- Web based supply chain management (eSCM)

- Value based strategic management of virtual organization (e.g. virtual organization sell plan, build plan, etc)

- Shared services in the way of creating virtual shared service centers (SSC) in virtual organization.

The major benefit of ERP based e-business information systems will be realized when production planning and procurement of all materials - production and non-production - will be, together with selling and buying, web-enabled and integrated.

Even if this demand is satisfied, although this is no easy task, at least one more essential issue shows up: Does the information system supply data, messages and information in time for the quickly changing contemporary life to be under control sufficiently and hence to be requisitely reliable? It is at this point that the ideas of anticipations and anticipatory systems (AS) and anticipatory systems thinking (AST) may be helpfully applied.

\section{Creation of Anticipatory Information Support for Virtual Organizations}

\section{The Idea of Anticipation and Anticipatory System Thinking}

The idea of anticipation has been known since the times of ancient Greece (Black, 1997), at least. On the Latin rather than ancient Greek basis, anticipation is expressed in a number of European languages (Britovsek, 1960). It was Rosen who, for the first time, linked the concept of anticipation with systems and systems theory (with the living systems theory) (Rosen, 1985). In his re- 
search, Rosen proceeded from the concept of living systems and from the possibility of one's management of their complexity. The author explains his approach: "When I was trying to develop the idea of an anticipatory system, I was interested more in how it behaved as such than in how it got to be anticipatory system." (Rosen, 1997). This means, that to him, the capacity of anticipation is a rather natural attribute, or at least a learned one. ASs can thus cover, as a concept, anticipatory living systems and ASs as their tools.

The fundamental cognitions of the Rosen's work have been summarized by Dubois $(1998,1999$, 2000, 2002, 2003): "Rosen, in the famous book Ancipatory Systems tentatively defined the concept of an anticipatory system: a system containing a predictive model of itself and/or of its environment, which allows it to state at an instant in accord with the model's predictions pertaining to a later instant." Dubois, in his series of conferences and books, made room for AS to evolve as mathematical and other tools of human thinking and action. To us, this means, that anticipation can receive support in mathematical and other methods, which can be developed, provided the AST is developed (about which we found no contributions so far).

The investigations carried out so far do not give a complete answer to the question: "What does the anticipation offer to the BSs and which characteristics define the anticipatory features of the BS?" This is equally true of a virtual organization. Hence we should start from making systems thinking an anticipatory one. By systems thinking we mean the synergy of few attributes (See: Mulej, et al., 2004). Its application allows for a requisite holism of human observing, thinking, decision-making, and action in general. This may include anticipation.

What is significant to AST is mainly its ability to support a requisitely holistic operation/behaviour in relation to its environment, and the direction of the behaviour of a human or organization as a BS, etc. (Potocan, 1998, 2000, 2002). The fundamental conditions of the AST concerning BSs include:

- A great flexibility (structure, functioning, behaviour), which enables a suitable ability of the BSs to function now and in future (Harman \& Porter, 1997; Jackson, 1991).

- A proper level of ergodics, e.g. a dynamic coordination and changing of goals of the current functioning and development (of both the whole, and the parts), which provides for an adequate adjustment of the BSs' behaviour to the current and future requirements of environment, (Lange, 1965), and

- Openness and dynamics of the BS in which an innovative functioning is taking place and which support a corresponding ability of the BS to anticipatorily treat both its own direction of (current and future) work and the behaviour of its own and other BS participants (owner, co-workers, co-opetitors, etc).

Anticipatory BSs are also largely determined by the basis for their conception and creation. The necessary starting point for creation of Anticipatory BSs lies in a new mental model of anticipatory system thinking (AST). The following attributes can be found typical of the AST concerning BSs (Flood, 1999; Potocan, 2000, 2002; Rebernik \& Mulej, 2000):

- The application of the interdisciplinary approach enables openness in the process of definition of the ASs to be treated, and of the area of their possible solutions; with AS application, the decisive person selects, for his or her work, only the sciences found requisite (Mulej, 1974, 2000; Rebernik, 2000; Rebernik \& Mulej, 2000) for his or her definition of the BS's attributes, which he or she has found crucial.

- Whether or not AST is adequate, also depends on how holistic are the definition, preparation, and consequences of the carrying out of a business operation; a requisite holism can be ensured by the consideration of cognitions, which are requisite for the concept, opera- 
tion, and organization of the BS. In practice, it is possible to reach only a partial holism of the business operation, which takes up a value in the interval between the total holism and total one-sidedness. Hopefully, this is a requisite holism (Kajzer, 1999; Mulej, 1974; Potocan, 2000).

- Standardization of business operations also makes an important starting point; by standardization we create comparability of the starting points and thus a quite unified treatment of various fields/subsystems of operation in different BSs. AST can lean upon the standards and have more time to work on the less predictable attributes ahead.

In our treatment of the basic starting points for a BS as an AS we face, at least, two types of problems. By defining/selecting the areas, aspects and related goals of the anticipatory operation we restrict the research field and consciously reduce our possible holism. Then we attempt to investigate the defined area (as holistically as possible, on the level of the requisite holism), but our main factor of judgment about the suitability is still the criterion of economics of the BS, because it is very costly in the future, if left aside now. The concept of "external economies" shows up as fictitious economics (See: WCED, 1998; Lafferty \& Meadowcroft, 2000; Ecimovic, Mulej, \& Mayur, 2002;).

On the basis of the presented conditions and starting points, the AST can be defined as an entity of the methodological approach, techniques and modes of work, which, in the BSs, indirectly and/or directly provides for the possible/anticipated future to have its impact on the current definition of objectives and goals of business operation, on the current and future directing of process operation and on the (re)-structuring of the BSs structure (Kajzer, 1999; Potocan, 2000, 2002).

AST, as defined by the above conclusions (on a preliminary basis, opening a discussion about AST), should help humankind control its general and individual future requisitely holistically. Hence, it should help humankind face entanglement of its current and future life/lives, and have a basis for mastering it, which is requisitely holistic. If this statement is correct, and it is derived from our experience, research, and reading the cited references about ASs, then a number of issues are surfacing. These issues about AST make the basis for a further investigation of the selected basic starting points, and characteristics of business AS. The objective starting points consist of the really existing needs and possibilities, the subjective ones of the acting persons' values and emotions, know-what, know-how, and talents involved in the process of observing, thinking, decision-making, and execution at stake (See: Mulej, 2000).

\section{The Anticipatory Business System}

The definition of the AST characteristics makes the starting points for the actual formation of a requisitely holistic support to the business operation, which will be an operation applicable to the BS at stake (Potocan, 1998, 2000; Potocan \& Mulej, 2003; Potocan et al., 2003). In the creation of this support we proceed from the process aspect of business operation, which defines a business process as an entity of the basic, management and information processes. The traditional central area of the business process is its basic process as the process directly creating the effects of business operation - products and/or services. For the basic process to have its support and to attain its efficiency and effectiveness it is, therefore, necessary to construct corresponding management and information processes.

All three processes are open to the environment and, at the same time, interlinked: from the reproduction (basic) process the interdependence proceeds to the management one, and from both of them to the information one. Because of the mentioned interdependences, the process of creation of the process of the anticipatory BS (ABS) can be defined as an entity of the following activities: 
- The creation of ABS starts by the synthesis of the selected dialectical system of viewpoints and the resulting analysis of the basic processes with the focus on the research of their current and development interdependencies. On their basis, the synthesis of the reproduction interdependence is carried out for the BS (i.e. its reproduction relations) in time or even before time.

- Then follows the creation of the ABS's management process, which will meet the needs of the defined basic process on all the crucial management levels in the BS (i.e. creation of adequate management relations enabling both a requisite efficiency and effectiveness of the BS operation) in time or even before time.

- The creation of ABS is concluded by the definition of the information needs and by the construction of the information system to support both the BS management and its operation of the basic process as a whole and per parts of the BS (i.e. creation of new information interdependences), again in time or even before time.

The presented concept enables the conception of the requisitely holistic ABS aimed to support business operation of the BS. In order to meet the needs of business operation of the individual parts of the BS it is necessary to create a dialectical system of specific and specialized (sub/partial) ABSs. The purpose-created and target-oriented ABSs make parts of a requisitely holistic anticipatory BS and, therefore, can be characterized as partial systems and/or subsystems of requisitely holistic ABSs.

A large variety of possible kinds, forms and types of partial or sub- ABSs, do not allow for their uniform definition or their totally holistic classification. However, it is possible to compose, in general, the framework of their operation. In the creation of the partial and/or sub- ABSs, we can proceed from:

- Aspects of treatment (e.g.: basic AS, management AS, information AS of the ABS)

- Function areas under consideration (e.g. purchase AS, production AS of the ABS)

- Viewpoints of research (e.g.: economic AS, technical AS of the ABS), and

- Various combinations of them.

In the formation of the AST and ASs in the BS under consideration we can apply anyone of the above stated starting points or their combination/s and synergies. In addition, numerous objective and subjective factors of business operation have an additional impact (indirectly or directly) on the AST in ABSs (at least).

Thus, the questions about the definition of the adequate treatment of the BS, and of the possibilities of a requisitely holistic support to business operation, matter indeed. But they can hardly be resolved, if the anticipation is none or short sighted or one-sided rather than requisitely holistic.

\section{A Critical View at Relations between Anticipation, Systems Theory, and Systems Thinking}

Ludwig von Bertalanffy (LvB), the founding father of the General Systems Theory (GST), was a mathematical biologist. He discovered the human lack of care for holism, concerned with the entire planet Earth, and required such a broad holism as a new worldview. To him GST was not merely a methodology, even less a method limited to description of (parts of) reality (Davidson, 1983; Elohim, 2001; Mulej, 2000). Thus, LvB (rightly) required what we might call a "totalsystem approach". To most humans, this is more than they find requisite in their own work and life framework. The idea of the GST as a broadest worldview has, gradually, come to be a formal 
methodology, which transfers some important insights from one specialised discipline to another and lets them benefit from transfers rather than from interdisciplinary co-operation (Davidson, 1983; ECMRS, 1972; Potocan, 2000; Schimenz, 2000; Mulej, 2001). A lot of benefit results, but it remains far away from LvB:

- Systems thinking, being the practice of holistic thinking, comes to be partially holistic.

- Systems theory, as its theoretical reflection and background, comes to be supportive of such partial holism, under the label of GST, in practice.

- Reductionism, which has been a very useful scientific approach over several centuries, but omitted complexity, comes to be fortified rather than partly replaced and partly complemented with a more holistic, interdisciplinary and transdisciplinary approach.

- The resulting innovations are partial, too, and cause many bad side effects, such as an urgent need for a "sustainable development" rather than a "nature-robbing, one-sided, one".

- The traditional human selfishness needs to include more interdependence into criteria of a good work and life, in order to be able to survive (Mulej, 2000; Mulej, 2001; Ecimovic et al., 2002).

In terms of the above quotations from references on anticipatory systems, the following groups of problems tend to show up, at least:

- The authors quoted above and others reporting about their work in Casys 1998, 1999, and 2000 (Dubois, 1998, 1999, 2000, 2002, 2003; Schwartz, 1998) tend to use the word "object, system, model" with no clear definition and delimitation. Thus, a number of misunderstandings may show up, and may be harmful to the very promising idea of anticipatory systems, because they may receive a too biased basis rather than one based on interdependence, taken in account on interdisciplinary and transdisciplinary levels of work.

- The same authors, who are obviously doing a very good job in their own selected areas, seem to tend to make a dangerous oversight. They tend to limit their own holism into a rather narrowly specialised view, inside which they are making a valuable contribution. Thus, they may produce wonderful tools, which might tend to be applied by people with worldviews of a much more limited scope than the one required (with full right) by LvB.

Hence, there is a need to pay more attention to the vocabulary, which is debated by Eric Schwarz (Schwarz, 1998), and to add to it more care for the worldview and other human attributes of the persons involved into „doing the science“, and especially the ones „doing the anticipation.“ We find the following delimitations necessary, at least (Mulej, 2000, Potocan, 2000):

1. Viewpoint of consideration (of an object as a system, covering the part of the object's attributes selected from the selected viewpoint);

2. System - in terms of contents versus in terms of mathematical formulation, and

3. Object - dialectical system - system - model.

What do we mean?

Every object of consideration exists in reality. Nobody is able, for natural reasons, to observe absolutely all of its attributes. Many thousands of professions have resulted from this fact. Every profession and every interest cause every person to, consciously or subconsciously, select a subsystem of attributes - from his or her or their selected viewpoint. Thus, a system is introduced as a mental picture of the object at stake. 
The system introduced in the above way, is holistic in terms of its mathematical definition, and one-sided in terms of its contents.

The object has all (!) attributes. The dialectical system consists of a (mathematically defined) system of systems (defined in terms of contents) for the reductionism to still meet the law of requisite holism, and for the insight to cause no serious oversights. The system has just been defined. The model pays tribute to the human need for a further reduction: it presents the system in a simplified way, e.g. by a picture, text, physical model, formula, etc., to make its basic idea transferable among people.

It is visible also from our quotation of LvB that he used to make no clear distinction, what a system is; neither did many other authors later on. This is no difficulty as long as only persons of the same profession/specialization are involved in discussion, consideration, and control. They tend to share the same viewpoint more likely than persons from different professions. To economists, mechanical engineers, electronic engineers, lawyers, accountants, etc., e.g. the same enterprise does not show up with the same attributes in the role of the most / only important ones. This example shows that it is dangerous to not exactly, explicitly, and clearly expose the viewpoint of consideration applied. We may have been reading with a lack of concentration, but we did not find this definition of the viewpoint selected for the given contribution by the given author in a vast majority of texts referenced. Some say it, in an indirect way, by denoting what they are dealing with, what is their purpose. In our experience and research about the approach and its consequences this kind of definition is acceptable inside the same experts / professionals group; much less so on an interdisciplinary level. The consequence is a partial or even fictitious holism, while the author, and even more so the reader, may expect a sufficient holism. On the other hand, any anticipation should provide for a reliable basis for the future behaviour, they say (and we quote) with full right.

This discussion and delimitation matter because the word system has a long set of definition in terms of its contents, e.g. in Webster dictionary (Britovsek, 1960; Black, 1997). The above discussion of the role of viewpoint lets us see, that every viewpoint, once selected, may produce a system - as long as the author keeps to the mathematical rule. It says that a system is an ordered set, which is made of a set of elements and a set of relations between them (plus with their environment/s). This mathematical definition can be met from every viewpoint selected and still present a whole, on mathematical terms. In terms of contents, this mathematical whole is no longer holistic, as soon as the system of viewpoints is not holistic, which means including totally all viewpoints, their relation and their synergies (in terms of LvB) Thus, the reality is that (Mulej, 1974, 2000, 2001):

- It is not a system, which exists, but an object. Calling an object a system with no definition of the viewpoint applied is a dangerous oversimplification taking a part for a whole.

- A system is a mental/emotional picture of an existing object, from a selected viewpoint, hence partial and biased and one-sided in its contents.

- A system is holistic from a mathematical formal viewpoint, although it is biased / onesided / partial in terms of contents.

Thus, the word system can have three quite different meanings, at least (Mulej, 1974, 2000, 2001; Mulej, Bastic et al., 2003; Mulej, Zenko et al., 2003):

- $\quad$ System $=$ object under consideration (which is the most frequent case in referenced sources of this text); this one may be misleading or good enough, depending on readers. 
- System = mathematical entity (which is fine, as long as it remains inside mathematics as the most abstract science).

- System = a biased mental and/or emotional picture / model of an object from a (explicitly or tacitly) selected viewpoint, from which it represents a set of attributes and a set of relations selected from the entire / total sets of them, as they exist.

If there is no explicit (!) delimitation between the notions of object, dialectical system, system, and model, it is again very hard for the reader to understand at which level of simplification the author is working in the given case. Hence, one should put it clearly.

There are many sciences and their theories, which are not in line with these definitions, but are very useful anyway. The point is they are not concentrating on complexity, but rather on complicatedness (Potocan, 2000, 2002). The difference is that the latter viewpoint concentrates on details of single components / elements rather than on their mutual relation, which is the topic of complexity. Both are needed for holism, and holism is needed for anticipation.

As a result of a practical shortcoming of several nice theories, beside / on basis of GST, other methodologies of holism surfaced inside systems movement (Jackson, 1991) and with the chaos and complexity theories (Mulej, 2000) or the Dialectical Network Thinking. They are all trying to find new ways of handling complexity, including the one concerning anticipation.

\section{Application of AST to Anticipatory Information Support for Virtual Organizations}

As defined earlier (in p. 2), virtual organizations are BSs, if viewed from a market relations viewpoint, alike all others, but different form the internal management, organizations, and economics viewpoints / aspects. Their information support may be hence nothing special in terms of support to BS's marketing operations, on one hand, and adapted to the higher flexibility of the BS's internal affairs, on the other hand.

Anticipation should be requisitely reliable in both parts of operation, of course. The issues of automation etc., which we have briefed in p. 3, are therefore less crucial / critical, although very important and difficult to resolve, than the issues of information contents. Thus one comes to the detecting of the information requirements resulting from the decisions and actions to be undertaken in the future and in the real time or earlier, perhaps even a lot earlier. This is the point for the AST to be most necessary, including the virtual organizations.

Due to bigger fluidity of the virtual organizations, the satisfying of their information requirements may be equally complex than their detecting and defining, or even more, because it: 1) depends on their detecting and defining, and 2) may lack time, sources and resources. This may happen because situations change so quickly in contemporary circumstances.

\section{Conclusions}

Let us summarize by the three theses put to discussion at the beginning. Creation of anticipatory information support for virtual organizations between system(s) theory and system thinking is a topic opening many essential issues and providing partial solution, so far.

All BSs that work in the modern turbulent and innovative environments have serious needs for anticipation of their potential future. This need defines their information requirement. If both the anticipation and the information are too partial rather then requisitely holistic, they can hardly be useful and beneficial. 
Therefore, both the anticipation and the information are more satisfactory, if they are backed by systems thinking, i.e. by observation, thinking, decision-making, and execution, that provide for the requisite holism, once a total holism cannot be attained. But, systems theory, in most of its currently known versions, tends to make the oversight of the importance and impact of the selected viewpoint/s. The Dialectical Systems Theory provides for a basis for observes, thinkers, authors, decision-makers and executing coworkers to use a dialectical system of viewpoints rather than a single one. Thus they can overcome their oversimplification and attain the requisite holism, therefore risking much less than by oversimplification.

Virtual organizations have no simpler situation, in this respect, but their habit to collect and dissolve partners as needed, may make them more capable of flexibility. This capacity may include more tendencies to be think and act in a requisitely holistic manner.

\section{References}

Black, J. (1997). A dictionary of economics. Oxford: Oxford University Press.

Britovsek, J. (Ed.). (1960). A guide through time and society (In Slovenian). Ljubljana: ZMK.

Davidson, M. (1983). Uncommon Sense: The life and thought of Ludwig Von Bertalanffy, father of general systems theory. Los Angeles: J. Tarcher.

Davidow, W. H., \& Malone, M. (1995). The virtual corporation. New York: Harper Business.

Dubois, D. (Ed.). (1998). Introduction to computing anticipatory systems. CASYS, 1 (2), 10-45.

Dubois, D. (Ed.). (1999). Computing anticipatory systems. CASYS, 2 (1), 67-102.

Dubois, D. (Ed.). (2000). Anticipatory systems. CASYS, 3 (2), 75-120.

Dubois, D. (Ed.). (2002). Computing anticipatory systems. CASYS 2002 - Fifth International Conference. Berlin: Springer Verlag.

Dubois, D. (Ed.). (2003). Sixth International Conference on Computing Anticipatory Systems. Liege: CHAOS.

Elohim, J. (2001). Unity through diversity. Vienna: Technical University of Vienna.

Ecimovic, T., Mulej, M. \& Mayur, R. (2002). Systems thinking and climate change system. Korte: SEM Institute for Climate Change.

European meeting on cybernetics and Systems research (ECMRS). (1972). Progress in cybernetics and systems research. Washington: ECMRS.

Englert J., Eymann, T., Hummel, T., \& Schoder, D. (1996). Beyond automation: A framework for supporting cooperation. In: Proceedings of $4^{\text {th }}$ European Conference on Information Systems. Lisbon: ECIS.

Flood, R. (1999). Rethinking the fifth discipline. London: Routledge.

Gloor, P. (2000). Making the E-business transformation. Berlin: Springer Verlag.

Goldman, J., Nagel, R., \& Preiss, K. (1995). Competitors and virtual organizations. New York, London: Van Nostrand Reinhold.

Harman, W. \& Porter, M. (1997). The new business of business. San Francisco: Berret.

Jackson, M. (1991). Systems methodologies for management. New York: Plenum Press.

Kajzer, S. (1999). Business systems. Systemica, 10, 46-67.

Lafferty, W. \& Meadowcroft, J. (2000). Implementing sustainable development: Strategies and initiatives in high consumption societies. Oxford: Oxford University Press.

Lange, O. (1965). Wholes and parts: A general theory of system behaviour. Oxford: Pergamon Press. 
Mulej, M. (1974). Dialekticna teorija sistemov (The Dialectical Systems Theory - In Slovenian). Ljubljana: University of Ljubljana, Faculty of Sports.

Mulej, M. (2000). Basics of systems thinking. Maribor: Faculty of Economics and Business, University of Maribor.

Mulej, M. (2001). Basics of systems theory. Maribor: FEB

Mulej, M., Bastic, M., Belak, J., Knez-Riedl, J., Pivka, M., Potocan, V., et al. (2003). Informal systems thinking or systems theory. Cybernetics and Systems, 34 (2), 71-92.

Mulej, M., Zenko, Z., Potocan, V., Kajzer, S., Umpleby, S. \& Ecimovic, T. (2003). (The system of) seven basic groups of systems thinking principles and eight basic assumptions of a general systems theory. In G. Chroust \& Ch. Hofer (Eds). IDIMT 2003: proceedings. Schriftenreihe Informatik (Bd 9). Linz. Universitaetsverlag R. Trauner, pp. 137-152.

Mulej, M., Potocan, V., Zenko, Z., Kajzer, S., Ursic, D., Knez-Riedl, J. et al. (forthcoming in 2004): How to restore Bertalanffian systems thinking. Kybernetes

Noris, G., Hurley, J,, Dunleavy, J., \& Balls, J. (2000). E-business and ERP: Transforming the enterprise. New York: Wiley and Sons.

Österle, H., Fleisch, E. \& Alt, R. (2000). Business networking: Shaping enterprise relationships on the internet. Berlin: Springer Verlag.

Palmer, J. (1998). The use of information technology in virtual organization. New York: Idea Group Publishing.

Potocan, V. (1998). Holistic decision-making as practical example of training for systemic thinking. In: Proceeding of IDIMT'98. Linz: Rudolf Trauner.

Potocan, V. (2000). Perspectives on business decision-making. Management, 5 (1), 13-28.

Potocan, V. (2002). Business systems: Sustainable development and anticipatory systems thinking. Management, 7 (1), 13-28.

Potocan, V. \& Mulej, M. (2003). On requisitely holistic understanding of sustainable development from business viewpoints. Systems Practice and Action Research, 16 (6), 421-436.

Potocan, V., Rebernik, M. \& Mulej, M. (2003). Business decision-making and anticipatory systems thinking. In: Engemann, K. \&, Lasker, G. (Eds.). Advances in decision technology and intelligent information systems. Vol. IV. Windsor (Ont., Canada): The International Institute for Advanced Studies in Systems Research and Cybernetics, pp. 41-45.

Rebernik, M. \& Mulej, M. (2000). Requisite holism, isolating mechanisms and entrepreneurship. Kybernetes, $29(9 / 10), 1126-1140$.

Rebernik, M. (2000). Anticipatory inadequacies of business economics and entrepreneurship theory. CHAOS, 3 (1), 315-332.

Rosen, R. (1985). Anticipatory systems. New York: Pergamon Press.

Rosen, R. (1997). Videotaped interview of Dr. Robert Rosen. Retrieved from Http: // Views.Vcu.Edu / Rsntpe.Html

Schiemenz, B. (2000). Interaktion, modelierung, kommunikation und lenkung in komplexen organisationen. Berlin: Duncker und Humblot.

Schwarz, E. (1998). The evolution of anticipation: A systemic holistic view. CASYS, 1 (2), 255-280.

World Commission on Environment and Development (WCED) (1998). Our common future on environment and development. Oxford: Oxford University Press 


\section{Biographies}

Vojko Potocan, born 1962, is an Assistant Professor of organization, management and systems theory, Faculty of Economics and Business, Department of Organization and Informatics, University of Maribor, Slovenia. He takes part in different international scientific conferences and realized a number of study visits on abroad. He has published +160 texts (+90 in foreign languages in 16 countries), including 4 books and edited proceedings and textbooks, mostly in Slovenia. The fields of his research interests are Organization, General Management and Sustainable Development.

Matjaz Mulej, born 1941, professor emeritus of systems and innovation theory, University of Maribor, Slovenia, has published +1000 texts in +30 countries, including +40 books, edited proceedings and textbooks, mostly in Slovenia, and about 40 articles in distinguished international journals. He is the author of the Dialectical Systems Theory (DST) as a methodology of holistic thinking, and USOMID methodology to be used for an informal application of DST. He mostly applies them to innovation of management and management of innovation in transitional countries, which resulted in his paradigm "Innovative Business and Innovative Society". He was 14 times a visiting professor abroad and gave about fifty further seminars at foreign universities on all continents. 